\title{
Sonographic Indicators for Treatment Choice and Follow-Up in Patients with Pleural Effusion
}

\author{
Ruza Stevic $\mathbb{D}^{1,2}$ Nikola Colic, ${ }^{2}$ Slavisa Bascarevic, ${ }^{1,3}$ Marko Kostic, ${ }^{3}$ Dejan Moskovljevic, ${ }^{3}$ \\ Milan Savic, ${ }^{1,3}$ and Maja Ercegovac ${ }^{1,3}$ \\ ${ }^{1}$ Faculty of Medicine, University of Belgrade, Serbia \\ ${ }^{2}$ Center for Radiology and MRI, Clinical Center of Serbia, Belgrade, Serbia \\ ${ }^{3}$ Clinic for Thoracic Surgery, Clinical Center of Serbia, Belgrade, Serbia
}

Correspondence should be addressed to Ruza Stevic; ruzastevic@yahoo.com

Received 20 December 2017; Revised 9 June 2018; Accepted 5 September 2018; Published 30 October 2018

Academic Editor: Jack Kastelik

Copyright (c) 2018 Ruza Stevic et al. This is an open access article distributed under the Creative Commons Attribution License, which permits unrestricted use, distribution, and reproduction in any medium, provided the original work is properly cited.

Aim. The aim of this study was to evaluate the role of thoracic sonography in treatment of pleural effusions and to identify sonographic indicators for surgical intervention. Materials and Methods. This study included 378 patients with pleural effusions. US characteristics of effusions as the echo structure and pleural thickening were analyzed. Regarding the US finding, the diagnostic or therapeutic procedure was performed. Results. The study included 267 male and 111 female patients, an average of 56.7 years. Infection was the most frequent cause of effusion. Two hundred sixty-nine patients had loculated and 109 free pleural effusion. Most frequent echo structure of loculated effusion was complex septate, whereas free effusion was mostly anechoic. Successful obtaining of the pleural fluid without real-time guidance was in $88 \%$ and under real-time guidance in $99 \%$ patients $(p<0.012)$. There was no significant difference in success rate between free and loculated effusion and regarding the echo structure ( $p=0.710$ and 0.126 , respectively). Complete fluid removal after serial thoracentesis or drainage was achieved in $86 \%$ patients. Forty-five patients with significantly thicker pleural peel and impairment of the diaphragmatic function than remaining of the group $(p<0.001)$ underwent surgery. Open thoracotomy and decortication was more frequently performed in patients with completely fixed diaphragm and complex, dominantly septated effusions. There is no significant difference in US parameters comparing to patients underwent VATS, but the number of VATS is too small for valid conclusion. Conclusion. Thoracic sonography is a very useful tool in the evaluation of clinical course and treatment options in patients with pleural effusions of a different origin.

\section{Introduction}

Chest ultrasonography (US) is a well-established and -validated imaging modality that has been used in diagnosing of pleural effusion, and it also provides highly useful guidance in invasive diagnostic and therapeutic procedures [1-5]. Ultrasound offers a number of advantages over other radiological methods: cost-effective imaging modality without risk of ionizing radiation, the sensitivity for the detection of pleural collection, and providing the examiner with realtime and immediate results. Compared with computed tomography (CT), ultrasound is more sensitive in distinguishing the pleural fluid from pleural thickening and pleural masses and in the detection of thin septations in loculated effusions $[2,3,6,7]$. Loculated collections pose challenge in the terms of the most efficient treatment selection. Intrapleural septa are of prognostic significance and may predict a more complicated clinical course. The aim of this study is to evaluate the role of thoracic sonography in treatment of pleural effusions, concerning the type and results of different procedures (thoracentesis, chest tube, and surgery), and to identify sonographic indicators for surgical intervention (VATS or open decortication).

\section{Materials and Methods}

2.1. Patients. Patients with pleural effusion of a different origin that underwent thoracic ultrasonography in the clinic 
for thoracic surgery from January 2014 to December 2015 were included in this investigation. Exclusion criteria comprised persons under 18 years, cardiac failure, and postthoracotomy and malignant effusions. Age and gender were recorded as well as the presumed diagnosis at the time of the referral (infectious, malignant, trauma, and others). All patients had chest radiography prior to chest sonography, and the patients with loculated effusion had chest computerized tomography (CT). In all patients who needed invasive procedures, the relevant lab tests were carried out (INR ratio and platelet count). Effusion was classified as left, right, or bilateral.

\subsection{Sonographic Examination. All US examinations were} performed by an experienced radiologist on the ultrasound machine Toshiba Nemio XG using a convex transducer with a frequency of $3.5 \mathrm{MHz}$. Since loculated fluid collections prevailed in our patients, scanning of the posterior chest wall in the sitting position was performed in most of them. In the bedside patients, the lateral approach was used. At an initial US assessment, the size, echo structure of pleural effusions, and the presence of pleural thickening or nodulations were evaluated. The estimation of the volume of effusion is performed using the qualitative approach: (1) minimal, if an effusion is seen within the costophrenic angle; (2) small, if the effusion is over the costophrenic angle but still within a one-probe range; (3) moderate, if the effusion is greater than a one-probe range but within a two-probe range; and (4) large or massive, if the effusion is bigger than a two-probe range [6]. Effusions were classified as anechoic, complex septate, complex nonseptate, and echogenic [2, 7]. According to the clinical condition, radiological findings, size, and US appearance of fluid collection, the decision about the therapeutic procedure has been made (thoracentesis, chest tube placement, and surgical treatment). The largest and most accessible pocket of fluid for thoracentesis was located, and puncture site, needle direction, and depth of penetration were determined with US. After identification of an appropriate site for thoracentesis, the freehand technique was performed using skin mark for collections where the observation of the needle in real time was not necessary. This nonguided approach was chosen in most patients because it does not require use of a sterile probe cover and an additional assistant. Real-time US-guided thoracentesis was performed in complex loculated and small fluid collections and in the patients in the intensive care unit. Large collections were drained using the standard technique and catheters of $18-20 \mathrm{Fr}$. The success rate of the invasive procedures was correlated with size, type, and US appearance of collections in all patients. The echo structure of pleural effusion, thickness of pleural peel, and function of the diaphragm was analyzed, and a comparison has been made concerning treatment options.

2.3. Statistical Analysis. Statistical analyses were performed using SPSS v.20.0 for Windows software (Chicago IL, USA). Descriptive statistics were used to summarize baseline demographic and clinical characteristics of patients. Results were expressed as mean \pm standard deviations for continuous variables and as percentages for categorical variables. Continuous variables were compared by using the T-test. Categorical variables were compared using the chi-square test. Statistical correlation among diaphragm movement and thickness of pleural peel was examined with the ANOVA test. A $p$ value $<0.05$ was considered statistically significant.

\section{Results}

The study included 267 male and 111 female patients, an average of $56.7 \pm 16.7$ years (18-87). Infection was the most common cause of effusion followed by other causes. Two hundred sixty-nine patients had loculated and 109 freeflowing effusions (Table 1). Most frequent echo structure of loculated effusion was complex septate (Figure 1(a)), whereas free effusion were mostly anechoic (Figure 1(c)). After the initial US examination, 125 cases were estimated as unsuitable for thoracentesis because of either small amount of pleural fluid or complex effusion with pleural peel. Thoracentesis was indicated in 253 cases. The "free-hand" technique after the skin mark was performed in 173 patients, and thoracentesis under real-time US guidance was done in 80 patients. Successful obtaining of the pleural fluid was $92 \%$ ( $88 \%$ for thoracentesis or drainage without real-time guidance and 99\% under real-time US guidance) $(p<0.012)$. Twenty of 21 unsuccessful thoracentesis was in small collection. There was no significant difference in success rate between different echo structures although the highest success rate was achieved in anechoic collections $(p=0.126)$ (Table 2). In 232 patients, repeated thoracentesis or drainage was performed as a therapeutic choice. Complete fluid removal after serial thoracentesis or drainage was achieved in 200 of $232(86 \%)$ patients. More than half of successfully drained collections had the complex echo structure (Table 3). In twenty-seven out of 32 patients with incomplete fluid evacuation, effusions were either complex nonseptate with thick fluid or with more thickened septations.

Pleural thickness in all groups was $5.6 \pm 1.5 \mathrm{~mm}$ with a significant difference between surgical treated and untreated group. The fixed diaphragm was dominantly found in loculated, complex septate collections and pleural peel thickness more than $6 \mathrm{~mm}$ ( $p<0.001$ both) (Figure 2).

Surgery was performed in 45 patients with a statistically significant difference in thickness of pleural peel and diaphragmatic dysfunction compared to the remaining of the group (Table 3). Open thoracotomy and decortication was more frequently performed in patients with completely fixed diaphragm and complex, dominantly septated effusions. VATS has been suitable in patients with free effusion, impaired diaphragm movement, and pleural peel thickness less than $6 \mathrm{~mm}$. There is no significant difference in US parameters between these two groups, but the number of VATS is too small for valid conclusion (Table 4). Surgery was not offered to patients with significant comorbidities, pulmonary embolism, and systemic diseases, regardless of 
TABLE 1: Characteristics of patients.

\begin{tabular}{|c|c|c|c|}
\hline Sex & Male (267) & Female (111) & \\
\hline Age & $57 \pm 15.6$ & $56.5 \pm 18.3$ & \\
\hline Diagnosis & & & Total \\
\hline Empyema & 116 & 39 & 155 \\
\hline Parapneumonic effusion & 61 & 30 & 91 \\
\hline Trauma & 40 & 11 & 51 \\
\hline Others* & 50 & 31 & 81 \\
\hline Type of effusion & & & Total \\
\hline Loculated & 185 & 84 & 269 \\
\hline Free & 82 & 27 & 109 \\
\hline Echo structure & & & Total \\
\hline Complex septate & 104 & 39 & 143 \\
\hline Complex nonseptate & 48 & 26 & 74 \\
\hline Echogenic & 35 & 19 & 54 \\
\hline Anechoic & 80 & 27 & 107 \\
\hline Treatment & & & Total \\
\hline Thoracentesis and chest tube & 177 & 76 & 253 \\
\hline Surgery & 37 & 8 & 45 \\
\hline
\end{tabular}

*Systemic autoimmune diseases, after cardiosurgery, pulmonary embolism, and abdominal pathology.

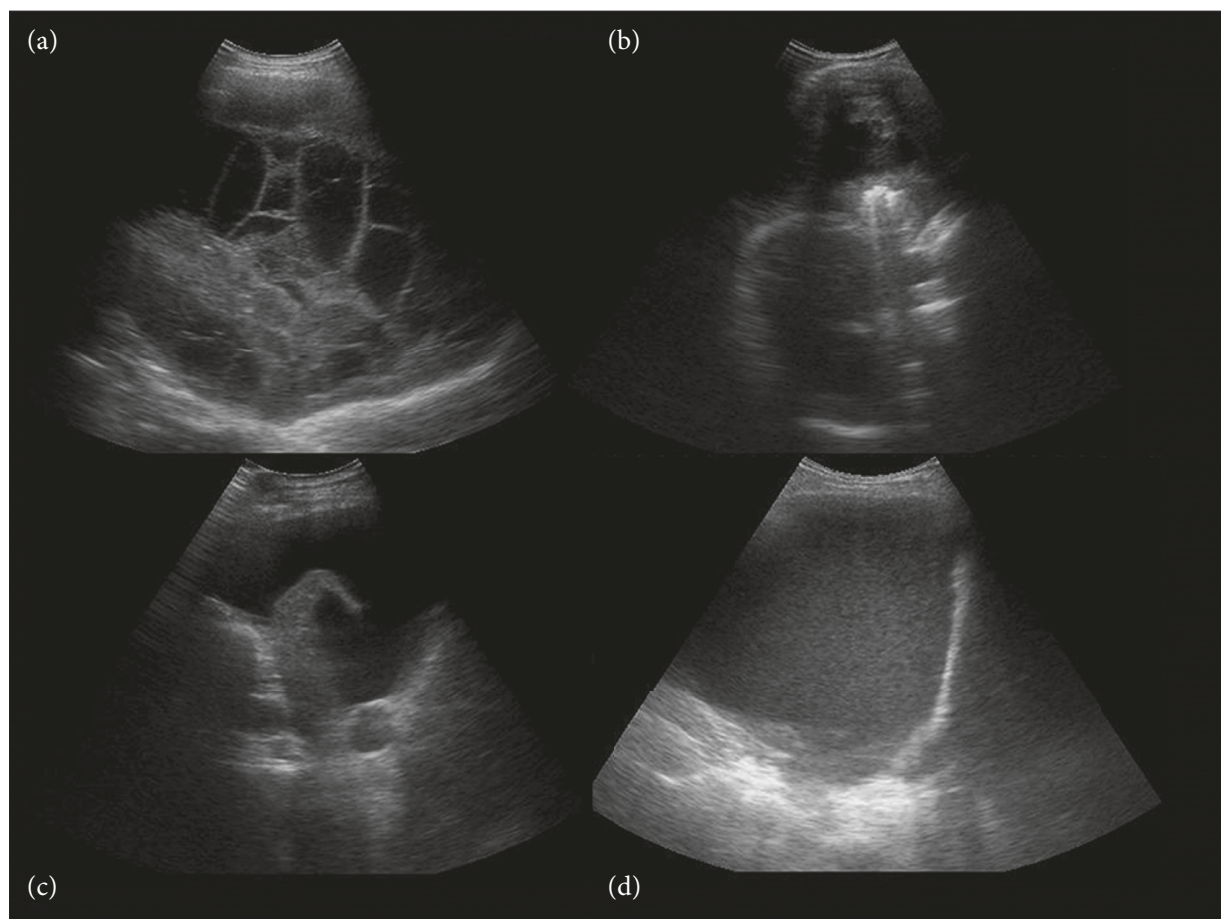

FIGURE 1: Representative sonographic findings for patients with different pleural effusions. Every chest US demonstrates the inner echo structure from complex septate (a) and nonseptate (b) to anechoic (c) and echogenic (d) pleural effusion.

characteristics of effusion, peel, and diaphragm. A number of patients did not give consent for surgical treatment.

\section{Discussion}

Chest sonography is a very convenient tool for evaluation of patients with pleural effusion in assisting thoracentesis and follow-up evaluation and in assessing treatment efficacy. It is well known that US is superior to radiography not only for assessing pleural effusion but also for diaphragm function. This study describes the role of sonography in the evaluation of pleural effusions regarding possible treatment options. Thoracentesis is usually the first diagnostic/therapeutic procedure in patients with established pleural effusion. Overall success rate of thoracentesis was high, and real-time US-guided thoracentesis was superior to the nonguided, skin mark technique. The main causes for thoracentesis failure in $8 \%$ patients were small collections with a complex echo structure and procedure without real-time monitoring. Lower success rate in thoracentesis or drainage without real-time guidance can be simply explained by shifting of both fluid collection and 


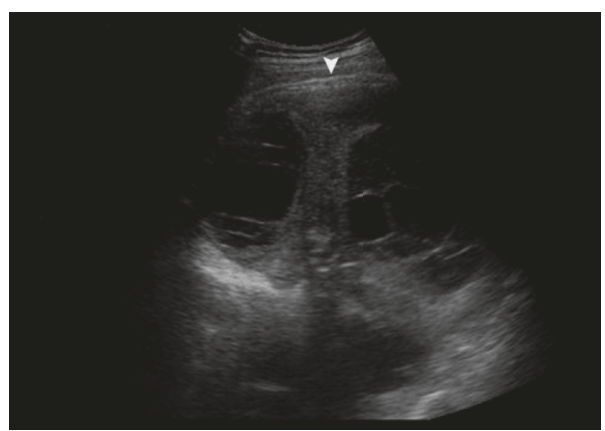

Figure 2: Chest sonography shows smooth pleural thickening (the arrow head) in complex septate effusion.

TABLE 2: Success rate of thoracentesis regarding the type, echo structure, and size of effusions.

\begin{tabular}{|c|c|c|c|c|c|c|c|}
\hline & & \multicolumn{2}{|c|}{ Unsuccessful } & \multicolumn{2}{|c|}{ Successful } & \multirow{2}{*}{ Total } & \multirow{2}{*}{ Sign } \\
\hline & & Number & $\%$ & Number & $\%$ & & \\
\hline \multirow{2}{*}{ Type of effusion } & Loculated effusion & 18 & 9 & 185 & 91 & 203 & \multirow{4}{*}{0.710} \\
\hline & Free-flowing effusion & 3 & 6 & 47 & 94 & 50 & \\
\hline \multirow[t]{2}{*}{ Total } & & 21 & 8 & 232 & 92 & 253 & \\
\hline & & Number & $\%$ & Number & $\%$ & Number & \\
\hline \multirow{2}{*}{ Thoracentesis } & Real-time US-guided thoracentesis & 1 & 1 & 79 & 99 & 80 & \multirow{3}{*}{$p<0.012$} \\
\hline & Without real-time guidance & 20 & 12 & 153 & 88 & 173 & \\
\hline \multirow[t]{3}{*}{ Total } & & 21 & 8 & 232 & 92 & 253 & \\
\hline & & Number & $\%$ & Number & $\%$ & Number & \multirow{6}{*}{0.126} \\
\hline & Complex septated & 11 & 10 & 104 & 90 & 115 & \\
\hline \multirow{5}{*}{ Echo structure } & Complex nonseptated & 4 & 7.5 & 49 & 92.5 & 53 & \\
\hline & Echogenic & 5 & 16 & 26 & 84 & 31 & \\
\hline & Anechoic & 1 & 2 & 53 & 98 & 54 & \\
\hline & & Number & $\%$ & Number & $\%$ & Number & \\
\hline & Small & 20 & 24 & 65 & 76 & 85 & \multirow{3}{*}{$p<0.001$} \\
\hline \multirow[t]{2}{*}{ Size of effusion } & Medium & 1 & 2 & 111 & 98 & 112 & \\
\hline & Large effusion & 0 & 0 & 56 & 100 & 56 & \\
\hline
\end{tabular}

TABLE 3: US characteristics of surgically and nonsurgically treated patients.

\begin{tabular}{|c|c|c|c|c|c|}
\hline \multirow{2}{*}{ Treatment option } & & \multicolumn{4}{|c|}{ Diaphragm function } \\
\hline & & Fixed & Impaired movement & Normal movement & Total \\
\hline Nonsurgically & & $49(15 \%)$ & $188(57 \%)$ & 93 & $330(100 \%)$ \\
\hline Surgically & & $15(33 \%)$ & $28(62 \%)$ & 2 & $45(100 \%)$ \\
\hline \multirow[t]{2}{*}{ Total } & & 64 & 216 & 95 & 375 \\
\hline & & \multicolumn{4}{|c|}{$p<0.001$} \\
\hline Treatment option & Complex septate & \multicolumn{3}{|c|}{ Echo structure } & Total \\
\hline Medicamentous & 34 & 22 & 25 & 52 & 133 \\
\hline Drainage/thoracentesis & 91 & 38 & 23 & 48 & 200 \\
\hline \multirow[t]{3}{*}{ Surgically } & 18 & 14 & 6 & 7 & 45 \\
\hline & 143 & 74 & 54 & 107 & 378 \\
\hline & \multicolumn{5}{|c|}{$p=0.090$} \\
\hline & \multicolumn{5}{|c|}{ Wall thickness } \\
\hline Treatment option & \multicolumn{2}{|r|}{$N$} & \multicolumn{2}{|c|}{ Mean } & Standard error mean \\
\hline Nonsurgically & \multicolumn{2}{|r|}{333} & \multicolumn{2}{|c|}{$5.39 \pm 1.45$} & 0.080 \\
\hline Surgically & \multirow{2}{*}{\multicolumn{2}{|c|}{45}} & \multicolumn{2}{|c|}{$7.04 \pm 1.44$} & 0.215 \\
\hline & & & .001 & & \\
\hline
\end{tabular}

skin mark with a change in the patient's position. During the real-time US-guided procedure, constant monitoring of the aspiration site helps avoiding thick septa or efficient disruption of thinner septa which enables successful fluid aspiration [8-14]. More than two-thirds of all patients had loculated effusion with the complex septate echo structure 
TABLE 4: US characteristics of surgically treated patients (open thoracotomy vs VATS).

\begin{tabular}{|c|c|c|c|c|c|}
\hline \multirow{2}{*}{ Treatment option } & & \multicolumn{4}{|c|}{ Diaphragm function } \\
\hline & & Fixed & Impaired movement & Normal movement & Total \\
\hline Open thoracotomy & & $15(37.5 \%)$ & $24(60 \%)$ & $1(2.5 \%)$ & $40(100 \%)$ \\
\hline VATS & & $0(0.0 \%)$ & $4(80 \%)$ & $1(20 \%)$ & $5(100 \%)$ \\
\hline \multirow[t]{2}{*}{ Total } & & 15 & 28 & 2 & 45 \\
\hline & & \multicolumn{4}{|c|}{$p=0.059$} \\
\hline Treatment option & \multicolumn{5}{|c|}{ Echo structure } \\
\hline $\begin{array}{l}\text { Open thoracotomy } \\
\text { VATS }\end{array}$ & $\begin{array}{c}17(42.5 \%) \\
1(20 \%) \\
18\end{array}$ & $\begin{array}{c}13(32.5) \\
1(20 \%) \\
14\end{array}$ & $\begin{array}{l}6(15 \%) \\
0(0 \%) \\
6 \\
p=0.075 \\
\end{array}$ & $\begin{array}{c}4(10 \%) \\
3(60 \%) \\
7\end{array}$ & $\begin{array}{c}40(100 \%) \\
5(100 \%) \\
45\end{array}$ \\
\hline & \multicolumn{5}{|c|}{ Wall thickness } \\
\hline Treatment option & \multicolumn{2}{|r|}{$N$} & \multicolumn{2}{|c|}{ Mean } & Standard error mean \\
\hline Open thoracotomy & \multicolumn{2}{|r|}{40} & \multicolumn{2}{|c|}{$7.25 \pm 1.4$} & 0.220 \\
\hline VATS & \multicolumn{2}{|r|}{5} & \multicolumn{2}{|c|}{$5.4 \pm 0.55$} & 0.245 \\
\hline
\end{tabular}

in half of them. This study and literature data confirmed that existence of intrapleural septa may predict a more complicated clinical course [6, 8-10, 15-20]. Our results and reported series show that the smaller number of complications and high success rate of thoracentesis even in complex loculated collections can be explained by the particular choice of the point of puncture in the skin markbased method and the constant view and following of the needle during the real-time US-guided intervention $[13,14,16,21,22,23,24,25]$. Cases with small or thick fluid collection (solid-like appearance) with the complex echo structure and thick septations were evaluated as nondrainable, so inefficient chest tube placement with possible complications has been avoided $[10,18,26]$. Failure of thoracentesis and/or drainage requires surgical treatment in selected patients. Results of this study concerning success rate of thoracentesis and drainage are in accordance with analyzed data that reported success rate from $62 \%$ to $97 \%$ depending on the echo structure of collection $[11,16,23]$. Preprocedural US can predict the likelihood of success of thoracentesis or drainage but not the patient outcome.

In the analyzed group of surgically treated patients, indication for surgery was based on diaphragmatic function, thickness of pleural peel, and characteristics of pleural fluid, in that order. Accurate identification of US predictors for open thoracotomy vs VATS in this study is limited by small number of patients treated with VATS procedures and requires further investigation on a larger sample size. However, preoperative US is a very useful tool in estimation of pleural peel thickness and diaphragmatic function and may help in planning the type of the procedure and predicting the length of surgery. US evaluation can be used repeatedly during patient treatment without possible risk of ionization associated with CT scan.

\section{Conclusion}

Thoracic sonography is a very useful tool in the evaluation of clinical course and treatment results in patients with pleural effusions of a different origin. Sonographic evidence of septa, pleural peel, and impair of diaphragm movement may indicate the need for surgical intervention. Indication for surgery and estimation of type of surgery (open vs VATS) may be based on serial US examinations with the high accuracy.

\section{Conflicts of Interest}

The authors declare that they have no conflicts of interest.

\section{Authors' Contributions}

Ruza Stevic and Maja Ercegovac participated in conception and design of the paper. Ruza Stevic, Nikola Colic, Slavisa Bascarevic, Marko Kostic, Dejan Moskovljevic, and Milan Savic contributed to collection, analysis, and interpretation of data. Ruza Stevic and Maja Ercegovac drafted the manuscript for important intellectual content.

\section{Acknowledgments}

This work was supported by the Ministry of Science and Technological Development of Serbia (Contract no. 175046).

\section{References}

[1] S. J. Koenig, M. Narasimhan, and P. H. Mayo, "Thoracic ultrasonography for the pulmonary specialist," Chest, vol. 140, no. 5, pp. 1332-1341, 2011.

[2] G. Soldati, G. Smargiassi, R. Inchingolo, S. Sher, S. Valente, and G. M. Corbo, "Ultrasound-guided pleural puncture in supine or recumbent lateral position-feasibility study," Multidisciplinary Respiratory Medicine, vol. 8, no. 1, p. 18, 2013.

[3] P. C. Yang, K. T. Luh, D. B. Chang, H. D. Wu, C. J. Yu, and S. H. Kuo, "Value of sonography in determining the nature of pleural effusion: analysis of 320 cases," American Journal of Roentgenology, vol. 159, no. 1, pp. 29-33, 1992. 
[4] M. Sperandeo, P. Filabozzi, A. Varriale et al., "Role of thoracic ultrasound in the assessment of pleural and pulmonary diseases," Journal of Ultrasound, vol. 11, no. 2, pp. 39-46, 2008.

[5] K. Stefanidis, S. Dimopoulos, and S. Nanas, "Basic principles and current applications of lung ultrasonography in the intensive care unit," Respirology, vol. 16, no. 2, pp. 249-256, 2011.

[6] E. Prina, A. Torres, and C. R. Ribeiro Carvalho, "Lung ultrasound in the evaluation of pleural effusion," Journal Brasileiro de Pneumologia, vol. 40, no. 1, pp. 1-5, 2014.

[7] P. H. Mayo and P. Doelken, "Pleural ultrasonography," Clinics in Chest Medicine, vol. 27, no. 2, pp. 215-227, 2006.

[8] R. Stevic, R. Jakovic, D. Masulovic, L. Nagorni-Obradovic, N. Mujovic, and D. Jovanovic, "Ultrasonography in diagnosis of thoracic diseases," Medicinski Pregled, vol. 63, no. 1-2, pp. 86-90, 2010.

[9] A. H. Diacon, M. H. Brutsche, and M. Soler, "Accuracy of pleural puncture site. A prospective comparison of clinical examination with ultrasound," Chest, vol. 123, no. 2, pp. 436-441, 2003.

[10] G. Gardelli, F. Feletti, A. Nanni, M. Mughetti, A. Piraccini, and M. Zompatori, "Chest ultrasonography in the ICU," Respiratory Care, vol. 57, no. 5, pp. 773-781, 2012.

[11] H. Yu, "Management of pleural effusion, empyema, and lung abscess," Seminars in Interventional Radiology, vol. 28, no. 1, pp. 75-86, 2011.

[12] S. Shankar, M. Gulati, M. Kang, S. Gupta, and S. Suriet, "Image-guided percutaneous drainage of thoracic empyema," European Radiology, vol. 10, no. 3, pp. 495-499, 2000.

[13] R. Stević, M. Ercegovac, R. Jaković et al., "Transthoracic ultrasonography in diagnosis and treatment of acute pleural empyema," Acta Chirurgica Iugoslavica, vol. 54, no. 3, pp. 129-136, 2007.

[14] C. J. Mercaldi and S. F. Lanes, "Ultrasound guidance decreases complications and improves the cost of care among patients undergoing thoracentesis and paracentesis," Chest, vol. 143, no. 2, pp. 532-538, 2013.

[15] G. L. Calligaro and C. F. N. Koegelenberg, "Pleural ultrasound-guided interventions: advances and future potential," Current Respiratory Care Reports, vol. 3, no. 2, pp. 45-51, Rep2014.

[16] F. Von Groote-Bidlingmaier and C. F. N. Koegelenberg, "A practical guide to transthoracic ultrasound," Breathe, vol. 9, no. 2, pp. 132-142, 2012.

[17] S. E. Kearney, C. W. H. Davies, R. J. O. Davies, and F. V. Gleeson, "Computed tomography and ultrasound in parapneumonic effusions and empyema," Clinical Radiology, vol. 55, no. 7, pp. 542-547, 2000.

[18] A. R. L. Medford and J. J. Entwisle, "Indications for thoracic ultrasound in chest medicine:An observational study," Postgraduate Medical Journal, vol. 86, no. 1011, pp. 8-11, 2010.

[19] C. F. Dietrich, G. Mathis, X.-W. Cui, A. Ignee, M. Hocke, and T. O. Hirche, "Ultrasound of the pleurae and lungs," Ultrasound in Medicine and Biology, vol. 41, no. 2, pp. 351-365, 2015.

[20] K.-Y. Chen, Y.-S. Liaw, H.-C. Wang, K. T. Luh, and P. C. Yang, "Sonographic septation: a useful prognostic indicator of acute thoracic empyema," Journal of Ultrasound in Medicine, vol. 19, no. 12, pp. 837-843, 2000.

[21] J. Almolla and G. Balconi, "Interventional ultrasonography of the chest; Techniques and indications," Journal of Ultrasound, vol. 14, no. 1, pp. 28-36, 2011.

[22] A. Perazzo, P. Gatto, C. Barlascini, M. Ferrari-Bravo, and A. Nicolini, "Can ultrasound guidance reduce the risk of pneumothorax following thoracentesis?," Jornal Brasileiro de Pneumologia, vol. 40, no. 1, pp. 6-12, 2014.

[23] D. Feller-Kopman, "Ultrasound guided thoracocentesis," Chest, vol. 129, no. 6, pp. 1709-1714, 2006.

[24] P. W. Jones, J. P. Moyers, J. T. Rogers, R. M. Rodriguez, Y. C. Lee, and R. W. Light, "Ultrasound-guided thoracentesis: is it a safe method?," Chest, vol. 123, no. 2, pp. 418-423, 2003.

[25] T. Havelock, R. Teoh, D. Laws, and F. Gleeson, "Pleural procedures and thoracic ultrasound: British Thoracic Society pleural disease guideline 2010," Thorax, vol. 65, no. 2, pp. 61-76, 2010.

[26] N. M. Rahman, A. Singanayagam, H. E. Davies et al., "Diagnostic accuracy, safety and utilization of respiratory physician-delivered thoracic ultrasound," Thorax, vol. 65, pp. $449-453,2010$. 


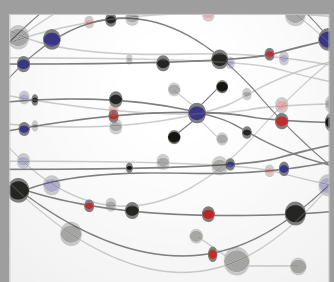

The Scientific World Journal
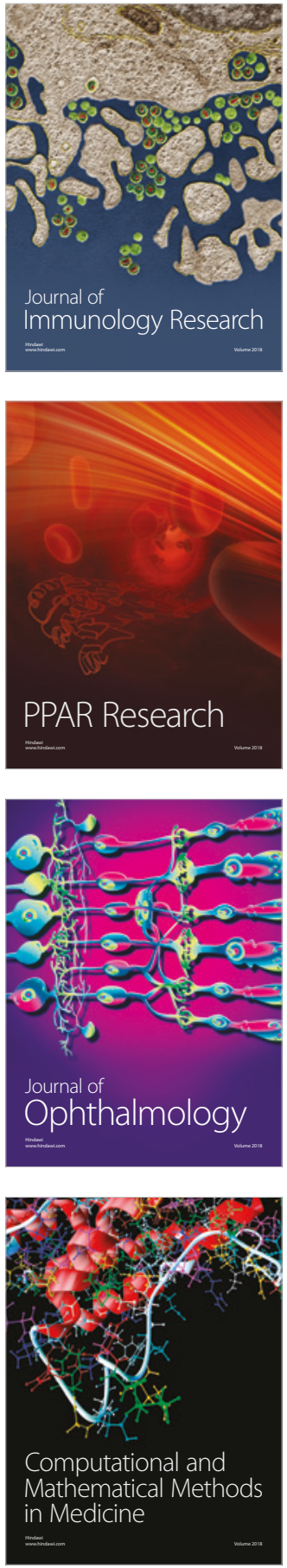

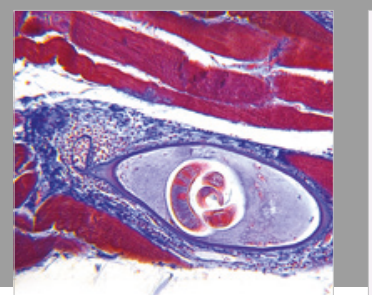

Gastroenterology Research and Practice

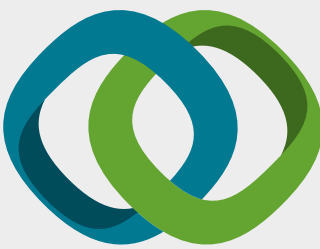

\section{Hindawi}

Submit your manuscripts at

www.hindawi.com
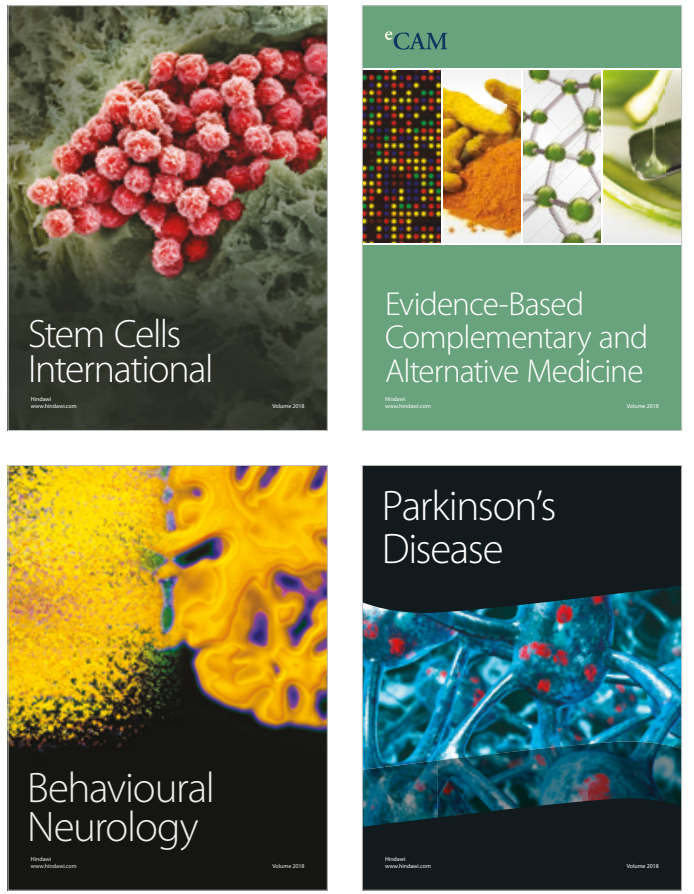

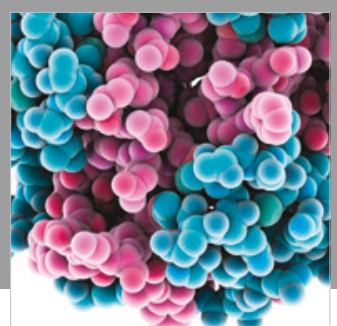

ournal of

Diabetes Research

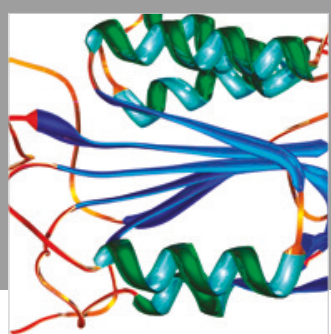

Disease Markers
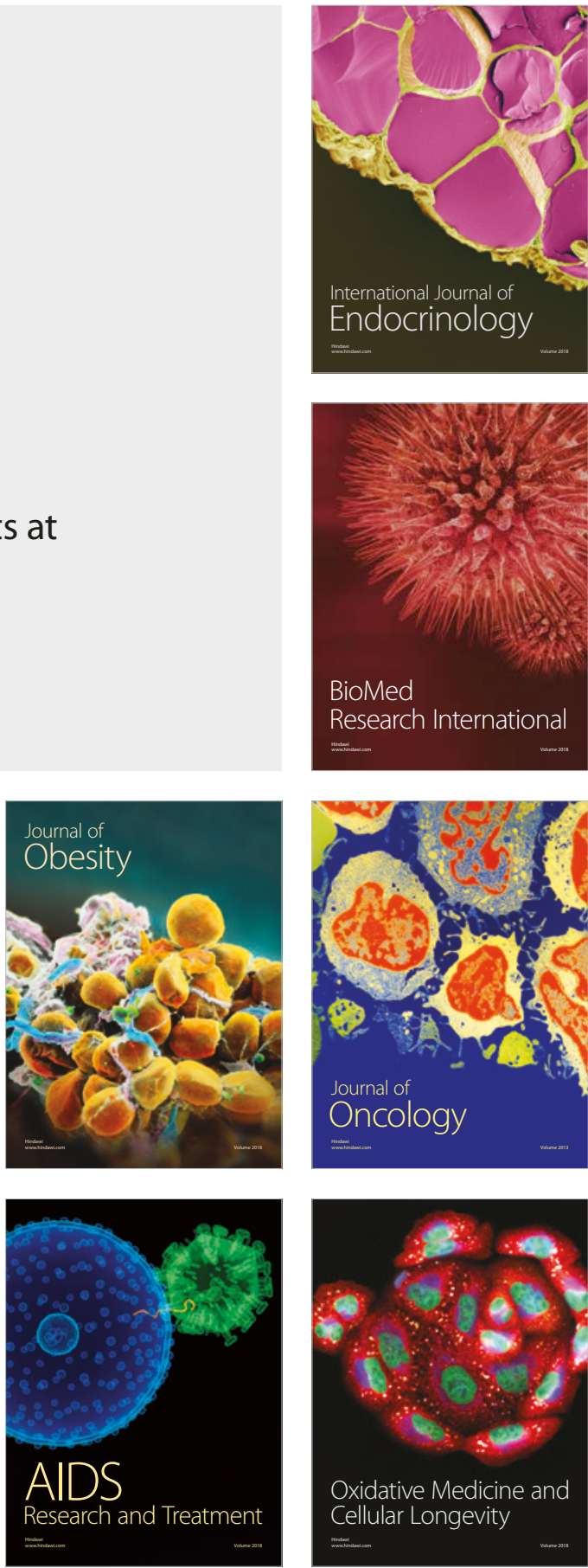